\title{
RESEARCH
}

Open Access

\section{Proper timing of control of hypertension and outcome in acute spontaneous intracerebral hemorrhage}

\author{
Ahmed Esmael ${ }^{1 *}$ (D, Wessam Fathi ${ }^{1}$, Mahmoud Abdelbadie ${ }^{2}$, Nehal Tharwat Mohammed El-sayed ${ }^{3}$, \\ Mahitab Ghoneim ${ }^{3}$ and Aymen Abdelnaby ${ }^{1}$
}

\begin{abstract}
Objective: Hypertension is the commonest cause of acute spontaneous intracerebral hemorrhage (ICH) which is life-threatening with a poor prognosis. The aim of this study is to evaluate the prognosis and blood pressure monitoring and control in patients presented by acute spontaneous $\mathrm{ICH}$.

Methods: One hundred and fifty patients presented by acute spontaneous ICH were classified according to the modified Rankin Scale $(\mathrm{mRS})$ score after discharge to 70 patients with better outcomes (mRS $=0-2$ ) while 80 patients with poor outcome ( $\mathrm{mRS}=3-6)$. Independent factors that were significantly related to prognosis were assessed by multivariate logistic regression. Spearman's correlation of the blood pressure monitoring in the acute $\mathrm{ICH}$ and the outcome was investigated.

Results: Systolic blood pressure at the onset of ICH was higher in the unfavorable outcome group $(P=0.009)$. Diastolic blood pressure $1 \mathrm{~h}$ after admission, systolic blood pressure $6 \mathrm{~h}$ after admission, and the systolic blood pressure $24 \mathrm{~h}$ after admission to hospital were lower in the favorable outcome group $(P=0.005, P=0.007$ and 0.01 , respectively). The independent variables related to favorable outcomes were younger age patients $(P=0.004)$, better level of consciousness at admission to hospital $(P=0.0001)$, and lower systolic blood pressure $6 \mathrm{~h}$ after admission to hospital $(P=0.005)$, decreased volume of hematoma $(P=0.05)$, supratentorial ICH $(P=0.02)$, and absence of intraventricular hemorrhage $(P=0.02)$.
\end{abstract}

Conclusions: Proper control and monitoring of the blood pressure in acute intracerebral hemorrhage must be initiated immediately especially in the first $6 \mathrm{~h}$ after hospitalization.

Trial registration: ClinicalTrials.gov ID: NCT04191863 'Retrospectively registered'

Keywords: Intracerebral hemorrhage (ICH), Hypertension, Glasgow Coma Scale (GCS), and modified Rankin Scale (mRS)

\section{Introduction}

Acute spontaneous non-traumatic intracerebral hemorrhage is a life-threatening illness with a poor prognosis and few proven treatments [1].

The commonest cause of primary spontaneous intracerebral hemorrhage ( $\mathrm{ICH})$ is hypertension, representing

\footnotetext{
* Correspondence: deltaneuro@mans.edu.eg

'Department of Neurology, Faculty of Medicine, Mansoura University,

Mansoura, Egypt

Full list of author information is available at the end of the article
}

about $60-70 \%$ of the causes of ICH. Sustained elevated blood pressure (BP) in the acute ICH carries a risk of increased hemorrhage, enlargement of $\mathrm{ICH}$ volume, and more poor prognosis [2, 3]. Sakamoto et al. 2013 observed that a $10-\mathrm{mmHg}$ increment in uncontrolled systolic blood pressure was found to be associated with poorer prognosis [4].

Management of blood pressure is the cornerstone in the treatment of cases of acute ICH [5]. Higher recovery and more favorable prognosis from intracerebral hemorrhage 
were seen in patients who accomplished the more systolic blood pressure $(\mathrm{sBP})$ control $(\geqq 20 \mathrm{mmHg})$ in the first hour and kept up for 1 week [6, 7]. Additionally, the analysis of modified Rankin Scores demonstrated improved functional outcomes with an intensive lowering of blood pressure [8].

However, the ATACH-II (Antihypertensive Treatment of Acute Cerebral Hemorrhage II) trial demonstrating that intensive reduction of blood pressure is not superior to standard blood pressure lowering in patients with acute hemorrhagic stroke [9].

The ideal management of BP after acute $\mathrm{ICH}$ is still debated and whether a higher intensive reduction of blood pressure after acute intracerebral hemorrhage may be better or not is still controversial [10]. Results from different randomized trials regarding the clinical guidelines for the management of hypertension in people with acute intracerebral hemorrhage (ICH) were conflicting [11]. These results indicate that the management of BP and the prognosis after acute spontaneous ICH are very complicated [12].

Therefore, analysis based on actual BP accomplished may be a more efficient method to assess the impact of BP management on the outcome of ICH [13].

In our research, BP management and prognosis were studied in patients with acute intracerebral hemorrhage to decide the perfect time to control BP to improve outcomes.

\section{Patients and methods}

\section{Patients and study design}

This study was a prospective cohort study conducted on 252 consecutive patients with acute first-ever spontaneous $\mathrm{ICH}$ within $24 \mathrm{~h}$ of onset, presented by acute spontaneous intracerebral hemorrhage $(\mathrm{ICH})$ were admitted to the Department of Neurology of Mansoura University Hospital, during the period from May 2018 to the end of April 2019. Seventy patients were excluded from our study according to the exclusion criteria. In the follow-up after 3 months, 23 patients died and 8 patients were missed. So, the final study and analysis of results included 150 patients with an average age of $70.1 \pm 13$ years included 68 females and 82 males (Fig. 1).

\section{Ethical approval}

The study was approved by the Institutional Review Board of Faculty of Medicine, Mansoura University, Egypt (proposal code: R.19.09.606-2019/09/04). All patients or first degree relatives provided written informed consent.

\section{Exclusion criteria}

Patients with secondary $\mathrm{ICH}$ were excluded from this study (like traumatic, hemorrhagic infarcts, arteriovenous malformation (AVM), bleeding tumors, or space- occupying lesion (SOL), or primary intraventricular hemorrhage (IVH) only without ICH. Also, patients with previous ischemic stroke or transient ischemic attacks (T1As) were excluded.

\section{Methods}

Patients were diagnosed by clinical examination and according to the initial $\mathrm{CT}$ brain after the onset of $\mathrm{ICH}$. Intensive management of blood pressure (BP) started once the diagnosis of $\mathrm{ICH}$ was established and continuous intravenous infusion of antihypertensive drugs and frequent BP monitoring. On the basis of the 2015 guidelines of American Heart Association (AHA), the SBP intensive group is to maintain below $140 \mathrm{mmHg}$ within $1 \mathrm{~h}$ from randomization [14]. The intravenous antihypertensive agents included sodium nitroprusside and nitroglycerin. Na nitroprusside started as continuous IV infusion of $0.5 \mu \mathrm{g} / \mathrm{kg} / \mathrm{min}$ and increased gradually up to a maximum dose of $10 \mu \mathrm{g} / \mathrm{kg} / \mathrm{min}$ or nitroglycerine may be used started as continuous an IV infusion of $5 \mu \mathrm{g} / \mathrm{kg} /$ min and increased gradually every $3-5$ min until control of hypertension up to a maximum dose of $200 \mu \mathrm{g} / \mathrm{kg} /$ $\mathrm{min}$. The doses of intravenous antihypertensive agents are reduced gradually; the SBP is maintained from 120 to $140 \mathrm{mmHg}$ for following 7 days or until hospital discharge. The use of oral antihypertensive agents, like angiotensin-converting enzyme inhibitors,, after the control of hypertension was utilized in step by step change from intravenous administration.

Patients were exposed to:

A) Complete history taking and complete clinical assessment including neurological and general examinations.

B) Initial Glasgow Coma Scale score at admission to hospital and the level of consciousness of patients according to GCS score were classified into 3 groups I (13-15), II (5-12), and III (3-4 ) according to Hemphill et al. 2001 [15].

C) Modified Rankin Scale (mRS) is a profoundly valid and reliable measure of disability and is broadly utilized for assessing stroke outcomes and the degree of disability. We characterized a favorable outcome as mRS ranging from zero up to two, while unfavorable outcomes ranging from 3 up to 6 [16]. Patients have partitioned into two main groups: the first group was favorable outcome patients (mRS equals $0-2$ ) and the second group was unfavorable outcome patients (mRS equasl 3-6).

D) Routine laboratory examinations including complete blood count $(\mathrm{CBC})$, blood sugar, coagulation tests, renal, and hepatic functions. 


\section{2 patients with the first-ever acute ICH}

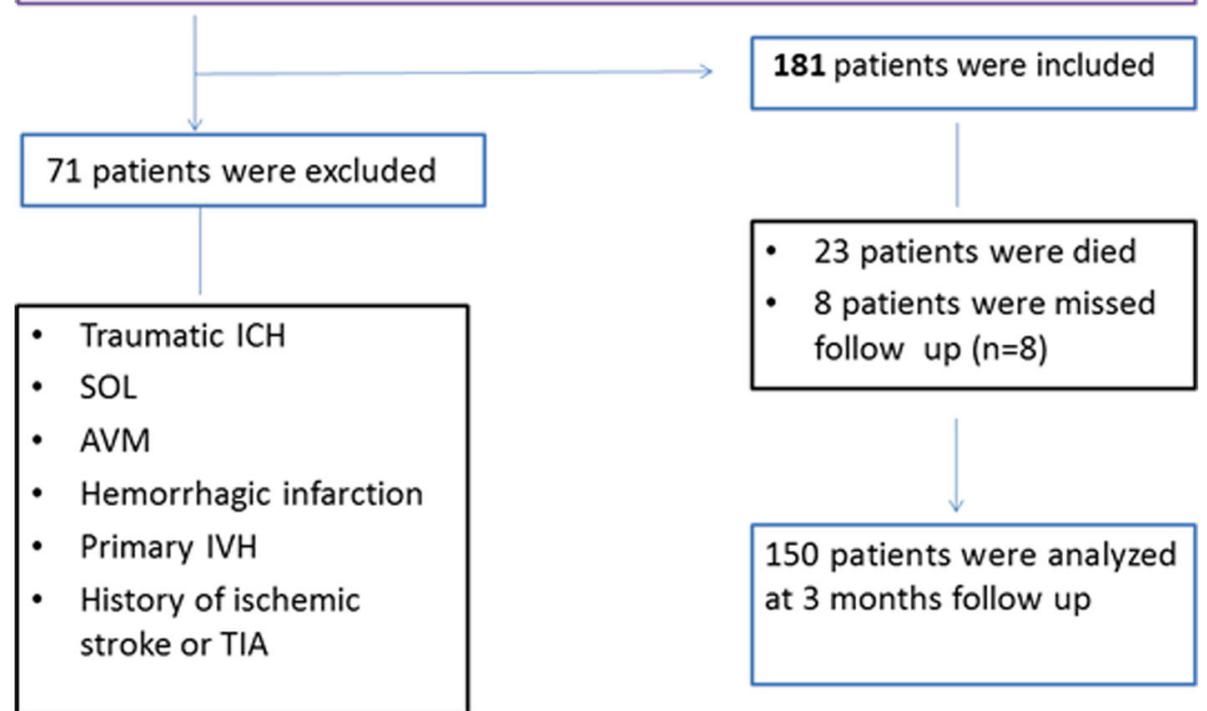

Fig. 1 Study flowchart showing the number of patients included in the final analysis

E) CT brain was accomplished for all patients at the onset of admission to the hospital to decide the characters of spontaneous ICH. The volume of the intracerebral hemorrhage was determined by utilizing the $\mathrm{ABC} / 2$ method: $(\mathrm{A})$ is the greatest diameter on the largest $\mathrm{ICH}$ cut, (B) is the diameter perpendicular to $\mathrm{A}$, while $\mathrm{C}$ is the number of axial cuts of ICH multiplied by the thickness of cuts $[17,18]$. Additionally, the location ICH (regardless of whether infra or supratentorial), and if there is intraventricular hemorrhage (IVH) or not, also, if there is a shift of midline structure or hydrocephalic changes were determined. Regarding ICH volume, patients were partitioned into two groups $\left(<30 \mathrm{~cm}^{3}\right.$ and $\left.\geq 30 \mathrm{~cm}^{3}\right)[19,20]$.

\section{Statistical analysis}

SPSS version 19.0 was utilized for statistical analysis. Data were collected and displayed as numbers proportions, mean \pm standard deviation, and range. Favorable and unfavorable groups were compared by chi-square measurement. For variables with ordinary distributions and homogeneous variances, Student's $t$ test was utilized to check the significant difference between the mean \pm standard deviation values in the two groups. $P$ value $<0.05$ were considered statistically significant results.

Multivariate logistic regression analysis was accomplished for the independent variables or factors that were accompanied by better outcomes: younger ages, GCS at admission, diastolic blood pressure $1 \mathrm{~h}$ after admission, systolic BP $6 \mathrm{~h}$ after admission, and systolic blood pressure $24 \mathrm{~h}$ after admission.

\section{Results}

One hundred and fifty patients with spontaneous $\mathrm{ICH}$ were studied in this work. $70.1 \pm 13$ year was the mean age of patients. Modified Rankin Scale score (mRS) after discharge was calculated and accordingly, patients were partitioned into two main groups: favorable outcome patients with better outcome (mRS equal $0-2 ; n=70$ ) and the second group was the unfavorable outcome with poor outcome patients (mRS equal 3-6; $n=80$ ).

Demographic data and risk factors of ICH patients were identified in Table 1. Younger age groups were associated with higher statistically significant favorable outcomes $(P=0.000)$. There was no significant difference in outcome regarding sex in both groups.

A higher non-significant percentage of cases had within normal renal and hepatic functions in patients with better outcomes $(P=0.31$ and $P=0.16$, respectively).

Regarding GCS at the onset, a GCS score of 13 to 15 was associated with higher statistically significant favorable outcomes and a GCS score of 3 to 4 was associated with higher statistically significant unfavorable outcomes $(P<0.0001)$. Also, there was a significantly prolonged duration of hospitalization in unfavorable outcome group of patients $(P=0.005)$.

The radiological findings of $\mathrm{ICH}$ demonstrated that an unfavorable outcome group of patients was associated with hematoma volume of $\geq 30 \mathrm{~cm}^{3}(P=0.0002)$, then the infratentorial location of ICH $(P=0.013)$, followed by IVH $(P=0.019)$. But, the shift of midline structures and hydrocephalic changes were not accompanied by significant unfavorable outcomes $(P=0.5$ and 0.77 , respectively) (Table 2 ). 
Table 1 Demographic data and risk factors of ICH patients

\begin{tabular}{|c|c|c|c|c|}
\hline \multicolumn{2}{|l|}{ Variable } & \multirow{2}{*}{$\begin{array}{l}\text { Favorable group (70) } \\
70(46.7 \%)\end{array}$} & \multirow{2}{*}{$\begin{array}{l}\text { Unfavorable group ( 80) } \\
-\end{array}$} & \multirow{2}{*}{$\frac{P \text { value }}{\text { NA }}$} \\
\hline mRS N (\%) & $0-2$ & & & \\
\hline & $3-6$ & - & $80(53.3 \%)$ & \\
\hline \multirow{4}{*}{$\begin{array}{l}\text { Age }(\text { mean } \pm \text { SD }) \\
70.1 \pm 13 \text { years }\end{array}$} & $<50$ & $11(15.7 \%)$ & $6(7.5 \%)$ & $P=0.000^{*}$ \\
\hline & $50-64$ & $31(44.3 \%)$ & $20(25 \%)$ & \\
\hline & $65-79$ & $20(28.6 \%)$ & $24(30 \%)$ & \\
\hline & $\geq 80$ & $8(11.4 \%)$ & $30(37.5 \%)$ & \\
\hline \multirow{2}{*}{$\begin{array}{l}\text { Sex } \\
\text { F/M (1:1.21) }\end{array}$} & Female (68) & $32(45.7 \%)$ & $36(45 \%)$ & $P=0.93$ \\
\hline & Male (82) & $38(54.3 \%)$ & $44(55 \%)$ & \\
\hline \multirow[t]{2}{*}{ HTN } & + & $47(67.1 \%)$ & $56(70 \%)$ & $P=0.84$ \\
\hline & - & $23(32.9 \%)$ & $24(30 \%)$ & \\
\hline \multirow[t]{2}{*}{ DM } & + & $10(14.3 \%)$ & $13(16.3 \%)$ & $P=0.91$ \\
\hline & - & $60(85.7 \%)$ & $67(83.7 \%)$ & \\
\hline \multirow[t]{2}{*}{ Hepatic disease } & + & $8(11.4 \%)$ & $15(18.7 \%)$ & $P=0.31$ \\
\hline & - & $62(88.6 \%)$ & $65(81.3 \%)$ & \\
\hline \multirow[t]{2}{*}{ Renal impairment } & + & $8(11.4 \%)$ & $17(21.2 \%)$ & $P=0.16$ \\
\hline & - & $62(88.6 \%)$ & $63(78.8 \%)$ & \\
\hline \multirow[t]{2}{*}{ IHD } & + & $7(10 \%)$ & $9(11.3 \%)$ & $P=0.98$ \\
\hline & - & $63(90 \%)$ & $71(88.7 \%)$ & \\
\hline \multirow[t]{2}{*}{ Anticoagulant or Antiplatelet } & + & $8(11.4 \%)$ & $12(15 \%)$ & $P=0.68$ \\
\hline & - & $62(88.6 \%)$ & $68(85 \%)$ & \\
\hline \multirow[t]{3}{*}{ GCS } & $13-15$ & $57(81.5 \%)$ & $20(25 \%)$ & $P<0.0001^{*}$ \\
\hline & $5-12$ & $9(12.8 \%)$ & $35(43.8 \%)$ & \\
\hline & $3-4$ & $4(5.7 \%)$ & $25(31.2 \%)$ & \\
\hline \multicolumn{2}{|c|}{ Duration of hospitalization (unite) } & $10.9 \pm 9.1$ & $21.7 \pm 8.7$ & $P=0.005^{*}(t$ test $)$ \\
\hline
\end{tabular}

mRS modified Rankin Scale, HTN hypertension, DM diabetes mellitus, IHD ischemic heart disease, GCS Glasgow Coma Scale *Statistically significant

Table 2 Radiological findings and prognosis in cases of $\mathrm{ICH}$

\begin{tabular}{llll}
\hline Radiological findings & Number of patients & Favorable outcome & Unfavorable outcome \\
\hline $\begin{array}{l}\text { Number of patients } \\
\text { Volume of ICH }\end{array}$ & 150 & 70 & 80 \\
$\quad<30 \mathrm{~cm}^{3}$ & 82 & $50(71.4 \%)$ & $32(40 \%)$ \\
$\quad \geq 30 \mathrm{~cm}^{3}$ & 68 & $20(28.6 \%)$ & $48(60 \%)$ \\
Site of ICH & & & \\
$\quad$ Supratentorial & 104 & $56(80 \%)$ & $48(60 \%)$ \\
$\quad$ Infratentorial & 46 & $14(20 \%)$ & $32(40 \%)$ \\
IVH & 52 & $17(24.3 \%)$ & $35(43.8 \%)$ \\
Midline shift & 48 & $20(28.6 \%)$ & $28(35 \%)$ \\
Hydrocephalus & 37 & $16(22.9 \%)$ & $21(2.3 \%)$ \\
\hline
\end{tabular}


Management of blood pressure in acute $\mathrm{ICH}$ patients reported in Table 3. The systolic BP at the onset of $\mathrm{ICH}$ was higher in the unfavorable outcome group $(P=$ 0.009). The diastolic BP $1 \mathrm{~h}$ after admission to the hospital was significantly lower in the favorable outcome group $(P=0.007)$. Systolic BP $6 \mathrm{~h}$ after admission to hospital and systolic BP $24 \mathrm{~h}$ after admission to hospital were significantly lower in the favorable outcome group ( $P=0.005$ and 0.01 , respectively).

Independent factors that were significantly related to prognosis were assessed by multivariate logistic regression. Table 4 demonstrate the independent factors associated with favorable prognosis at discharge from hospital, were young age (OR 2.31 95\% CI 1.97-2.93 and $P=0.004)$, better level of consciousness at admission(OR 4.112, 95\% CI 3.21-6.15, and $P=0.0001$ ), and lower systolic BP $6 \mathrm{~h}$ after hospitalization (OR 2.22, 95\% CI 1.86-2.87 and $P=0.005)$, decreased volume of hematoma $<30 \mathrm{~cm}^{3}$ (OR 1.39, 95\% CI 1.13-2.11, $P=$ 0.05), supratentorial ICH (OR 1.51, 95\% CI 1.27-2.42, and $P=0.02$ ), and absence of IVH (OR 1.39, 95\% CI 1.13-2.11 and $P=0.02$ ). Other factors, such as sex or hydrocephalus, and patients with IVH, showed no significant associations with clinical outcomes.

Figure 2 demonstrated that the area under curve equal to 0.57 showed that the cut-off value was $135 \mathrm{mmHg}$ (sensitivity was $43.9 \%$ and specificity was $73.7 \%$ ).

Spearman correlation showed a high positive significant correlation between the systolic blood pressure $6 \mathrm{~h}$ after admission, age, and volume of ICH with the modified Rankin Scale $(r=0.79, P<0.01$, and $r=0.86, P<$ 0.001 and $r=0.75, P<0.01$, respectively). But, there was

Table 3 Management of blood pressure in acute $\mathrm{ICH}$

\begin{tabular}{llll}
\hline Blood pressure (BP) & $\begin{array}{l}\text { Favorable group } \\
(n=70)\end{array}$ & $\begin{array}{l}\text { Unfavorable group } \\
(n=80)\end{array}$ & $P$ value \\
\hline At arrival & & $191.6 \pm 23.9$ & $P=0.009^{*}$ \\
Systolic & $180.6 \pm 29.3$ & $102.4 \pm 19.8$ & $P=0.146$ \\
Diastolic & $99.1 \pm 20.9$ & & \\
After $1 \mathrm{~h}$ & & $150.3 \pm 19.9$ & $P=0.095$ \\
Systolic & $147.6 \pm 20.1$ & $85.6 \pm 16.7$ & $P=0.007^{*}$ \\
Diastolic & $80.1 \pm 15.5$ & & \\
After 6 h & & $144.3 \pm 18.2$ & $P=0.005^{*}$ \\
Systolic & $136.1 \pm 16.4$ & $P=0.135$ \\
Diastolic & $79.7 \pm 12.9$ & $83.1 \pm 12.8$ & \\
After 24 h & & & $P=0.01^{*}$ \\
Systolic & $135.6 \pm 16.9$ & $142.0 \pm 16.4$ & $P=0.236$ \\
Diastolic & $77.9 \pm 13.4$ & $80.6 \pm 12.7$ & \\
At discharge & & & $P=0.122$ \\
Systolic & $125.8 \pm 16.7$ & $127.2 \pm 18.5$ & $P=131$ \\
Diastolic & $77.8 \pm 12.5$ & $80.1 \pm 11.4$ & \\
\hline
\end{tabular}

*Statistically significant
Table 4 The independent factors that were highly associated with the outcome of $\mathrm{ICH}$

\begin{tabular}{llll}
\hline Variables & O R & $95 \% \mathrm{Cl}$ & $P$ \\
\hline Age & 2.31 & $1.97-2.93$ & $0.004^{* *}$ \\
GCS at admission & 4.112 & $3.21-6.15$ & $0.0001^{* *}$ \\
Systolic blood pressure after $6 \mathrm{~h}$ & 2.22 & $1.86-2.87$ & $0.005^{* *}$ \\
Volumes of ICH & 1.761 & $1.32-2.54$ & $0.01^{*}$ \\
Site of ICH & 1.51 & $1.27-2.42$ & $0.02^{*}$ \\
IVH & 1.39 & $1.13-2.11$ & $0.05^{*}$ \\
\hline
\end{tabular}

IVH intraventricular hemorrhage, ICH intracerebral hemorrhage, GCS Glasgow Coma Scal, OR odds ratio, $\mathrm{Cl}$ confidence interval

* Statistically significant

**Stronger statistical significant

a strong negative significant correlation between the GCS with the modified Rankin Scale $(r=-0.91, P<$ 0.001) (Fig. 3).

\section{Discussion}

Hypertension during acute spontaneous ICH is highly accompanied by hematoma enlargement, more edema surrounding the $\mathrm{ICH}$, and more morbidity and mortality [21]. So, management of blood pressure has a significant role in the management of acute spontaneous intracerebral hemorrhage [9, 22, 23].

Hemphill et al. 2015 prescribed that the systolic blood pressure in cases with spontaneous acute intracerebral hemorrhage must be brought down to $<140 \mathrm{mmHg}$ at the earliest opportunity and kept controlled at this level for about 7 days [14].

In our study, the prognostic risk factors that determined the outcome at discharge were age, GCS at admission to hospital, and systolic BP $6 \mathrm{~h}$ after admission to hospital. Age and GCS at admission were not liable for modification while the prognostic factor that was liable for modification and agreeable to treatment mediation was systolic BP $6 \mathrm{~h}$ after admission to hospital.

In this manner, once $\mathrm{ICH}$ has been diagnosed, the antihypertensive medication must be initiated immediately [24]. The control of BP added to the regulation of cerebral blood flow and metabolism [25].

In our study, older age patients were associated with unfavorable outcomes in cases of acute spontaneous intracerebral hemorrhage $(P=0.004)$. These results indicated that older age patients had bad general status; bad nourishing status and disabled renal or hepatic functions were associated with poor outcomes. This was like the study of Rådholm et al. 2015 who found that older patients with acute ICH experience worse outcomes, including death and disability. Advanced age most likely was associated with several clinical factors connected to poor outcomes, such as stroke severity (high NIHSS score), hematoma qualities (like an intraventricular extension), and co-morbid medical condition [26]. 


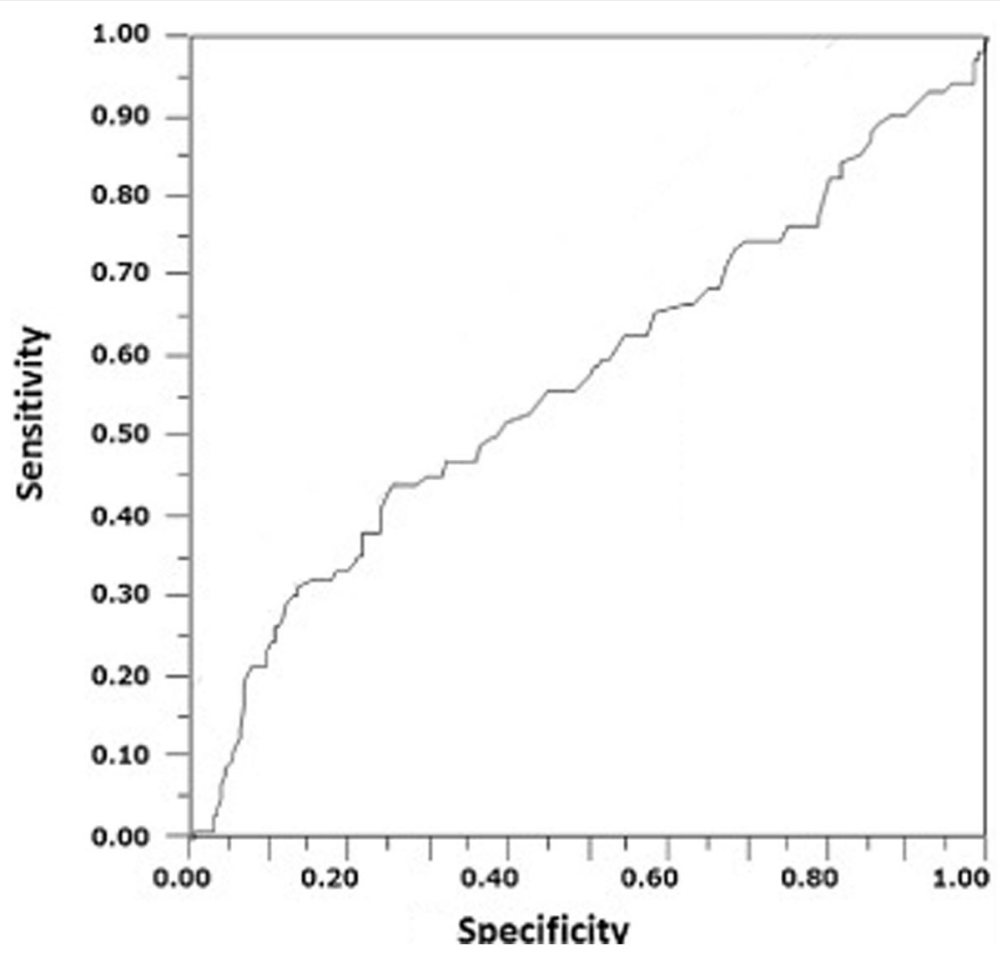

Fig. 2 ROC curve evaluation of systolic BP $6 \mathrm{~h}$ after admission and unfavorable outcome after discharge from hospital

In our study, the consciousness level at admission determined by GCS was the most independent variables that were significantly related to the outcome in cases of acute spontaneous ICH (OR 4.112, 95\% CI 3.21-6.15 and $P=0.0001$ ). Correspondingly, Sang Hoon Lee et al. 2015 concluded that the initial GCS score was a strong predictive factor for the prognosis of thalamic ICH [27].

There are studies reported that antiplatelet drugs, anticoagulants, renal, and liver impairment were associated with poor prognosis in cases of ICH. Hokari M et al. 2018 concluded that patients with $\mathrm{ICH}$ who were on antiplatelet and anticoagulants were more likely to have a poor prognosis [28]. Ravi Garg and José Biller 2019 who study the recent advances in spontaneous intracerebral hemorrhage stated that antiplatelet and anticoagulants were found to be associated with a larger volume of intracerebral hemorrhage, more incidences of hematoma enlargement, and poorer outcome $[29,30]$. But, in our study, these risk factors were more marginally related (but not statistically significant) with unfavorable outcomes.

In our study, intraventricular hemorrhage (IVH) was observed to have a significant association with unfavorable outcomes (OR 1.39, 95\% CI 1.13-2.11, and $P=$ 0.02). Yogi N et al. 2019 clarify that the intraventricular hemorrhage leads to CSF stream obstruction by blood clots followed by obstructive hydrocephalus and brain edema [31]. Not only the presence of IVH is important for the prognosis but also, the severity of IVH extension is important for the prognosis as concluded by Gabriela et al. 2019 who demonstrated that Graeb score $\geq 5$ is an independent predictor of poor outcome at hospital discharge after spontaneous ICH [32]. The Graeb scale is a quantitative scale for IVH extension with a score ranging from 0 to 12 points and higher scores indicating increased IVH volumes.

The size of the ICH was another factor demonstrating that larger $\mathrm{ICH}$ volume $\geq 30 \mathrm{~cm}^{3}$ was associated with unfavorable outcomes in our study (OR 1.39, 95\% CI $1.13-2.11, P=0.05)$. Numerous researchers found that $\mathrm{ICH}$ volume was a very strong predictor of functional outcome and mortality [33, 34].

In our study, supratentorial $\mathrm{ICH}$ was found to be significantly accompanied by favorable outcomes in comparison to infratentorial ICH (OR 1.51, 95\% CI $1.27-2.42$ and $P=0.02$ ). Similarly, Ruiqi Chen et al. 2019 concluded that cerebellar and brain stem ICH associated with higher case fatality and poor outcomes [35]. However, a population-based study of the influence of ICH location on outcome stated that the impact of supratentorial ICH location on outcome stays hazy [36].

The multivariate logistic regression analysis was accomplished for the proper time for control of blood pressure showed that diastolic blood pressure $1 \mathrm{~h}$ after admission, systolic BP $6 \mathrm{~h}$ after admission, and systolic blood pressure $24 \mathrm{~h}$ after admission were accompanied by the favorable outcome. Similarly, Huan-Xin et al. 


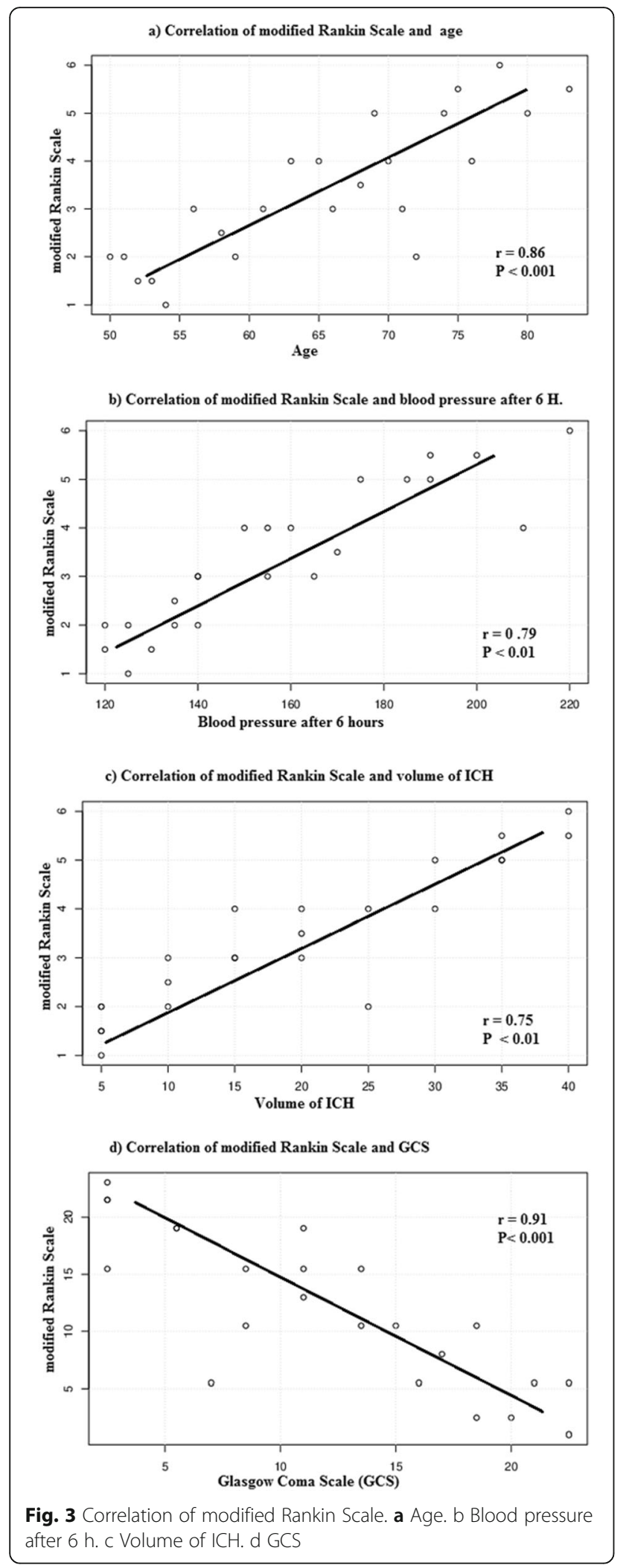

Fig. 3 Correlation of modified Rankin Scale. a Age. b Blood pressure after 6 h. c Volume of ICH. d GCS
2018 concluded that high systolic or diastolic blood pressure during $24 \mathrm{~h}$ of $\mathrm{ICH}$ onset is accompanied by the 90-day neurological outcome, and the first 24-h BP plays a critical role in the neurological outcome of hemorrhagic stroke [37]. Also, the second Intensive Blood Pressure Reduction in the Acute Cerebral Hemorrhage Trial (INTERACT2) assessed the predictive value of $\mathrm{BP}$ variability in outcomes for $\mathrm{ICH}$ patients (within $6 \mathrm{~h}$ after symptom onset) targeting BP levels to lower than $140 \mathrm{mmHg}$. BP was measured five times during the first $24 \mathrm{~h}$ and twice daily until day 7 after $\mathrm{ICH}$ onset [38]. Moreover, the Stroke Acute Management with Urgent Risk Factor Assessment and Improvement studies included patients within $3 \mathrm{~h}$ after symptom onset with initial SBP exceeding $180 \mathrm{mmHg}$. The SBP was lowered to $120-160 \mathrm{mmHg}$ [39]. In our study, the systolic blood pressure $6 \mathrm{~h}$ after admission was significantly lower in patients with better outcomes (OR 2.22, 95\% CI 1.862.87 , and $P=0.005)$. So, it is very important to decrease the blood pressure within $6 \mathrm{~h}$ after hospitalization. Lower systolic blood pressure $24 \mathrm{~h}$ after admission to the hospital was significantly associated with a more favorable outcome group $(P=0.01)$. Consequently, intensive blood pressure control is necessary from hospital admission up to the following $24 \mathrm{~h}$. In INTERACT2 study [40], a serious decrease of systolic blood pressure $\leq 140 \mathrm{mmHg}$ in patients with acute spontaneous ICH did not affect the primary outcome. However, the analysis of the modified Rankin scale suggested that intensive therapy improved the outcomes.

The cut-off estimation of systolic BP $6 \mathrm{~h}$ after admission to the hospital was $135 \mathrm{mmHg}$. The study of Krista LimHing and Fred Rincon 2017 demonstrated a tendency toward hematoma growth from baseline to $24 \mathrm{~h}$ in the intensive treatment group (SBP > $140 \mathrm{mmHg}$ ) [21].

However, our results demonstrated that $\mathrm{BP}$ at discharge was not associated with significant difference in the outcome $(P=0.122)$. Accordingly, intensive blood pressure control of at least $24 \mathrm{~h}$ after admission to the hospital was the most important. Stacy Chu and Lauren Sansing 2017 and Qureshi et al. 2010 mentioned that patients who had more aggressive SBP reduction in the first $24 \mathrm{~h}$ demonstrated patterns toward diminished hematoma expansion and better outcomes [41, 42].

\section{Limitations}

Our study had several limitations; first, it was a singlecenter observational study. However, our hospital is the most famous reference center in Mansoura City for critical neurological patients. The second was the inclusion and exclusion criteria that restrict the eligibility of patients. The third limitation was a relatively short observation which may underestimate or overestimate clinical 
benefits or loss of efficacy of management of hypertension in cases of $\mathrm{ICH}$.

\section{Conclusion}

Younger ages, a better level of consciousness at admission to hospital, and lower sBP $6 \mathrm{~h}$ after admission to hospital were the most significant predictors of favorable outcomes in patients with acute spontaneous intracerebral hemorrhage. Anti-hypertension medication must be initiated immediately after the diagnosis of $\mathrm{ICH}$ is confirmed to bring down the BP in the first $6 \mathrm{~h}$ after hospitalization.

\section{Acknowledgements}

Not applicable.

\section{Authors' contributions}

All authors contributed to the conduct of the study. AE, the main author, wrote the first draft of the manuscript. All authors reviewed and edited the manuscript and approved the final version.

\section{Funding}

This research received no specific grant from any funding agency in the public, commercial, or not-for-profit sectors.

\section{Ethics approval and consent to participate}

This study was approved by the local ethics committee Institutional Research Board (IRB) of Departments of Neurology, Mansoura Faculty of Medicine, Egypt. RP.20.01.54-2020/01/10. Patients and their families were told about the study in detail, and written informed consent was taken.

\section{Competing interests}

The authors declare that they have no competing interests.

\section{Author details}

${ }^{1}$ Department of Neurology, Faculty of Medicine, Mansoura University, Mansoura, Egypt. ${ }^{2}$ Department of Cardiology, Faculty of Medicine, Mansoura University, Mansoura, Egypt. ${ }^{3}$ Department of Radiology, Faculty of Medicine, Mansoura University, Mansoura, Egypt.

Received: 13 January 2020 Accepted: 22 June 2020

Published online: 06 July 2020

\section{References}

1. Cordonnier C, Demchuk A, Ziai W, Anderson CS. Intracerebral hemorrhage: current approaches to acute management. Lancet. 2018;392(10154):125768. https://doi.org/10.1016/S0140-6736(18)31878-6.

2. Al-Mufti F, Thabet A, Singh T, El-Ghanem M, Amuluru K, Gandhi C. Clinical and radiographic predictors of intracerebral hemorrhage outcome. Intervent Neurol. 2018;7:118-36. https://doi.org/10.1159/000484571.

3. Lattanzi $\mathrm{S}$, Silvestrini M. Blood pressure in acute intracerebral hemorrhage. Ann Transl Med. 2016;4(16):320. https://doi.org/10.21037/atm.2016.08.04.

4. Sakamoto Y, Koga M, Toyoda K. Systolic blood pressure after intravenous antihypertensive treatment and clinical outcomes in hyperacute intracerebral hemorrhage: the stroke acute management with urgent riskfactor assessment and improvement-intracerebral hemorrhage study. Stroke. 2013;44:e153.

5. Alejandro A. Rabinstein, Optimal Blood Pressure After Intracerebral Hemorrhage Still a Moving Target. Stroke. 2018;49:275-6. https://doi.org/10. 1161/STROKEAHA.117.020058.

6. de Oliveira Manoel AL, Goffi A, Zampieri FG, Turkel-Parrella D, Duggal A, Marotta TR, Macdonald RL, Abrahamson S. The critical care management of spontaneous intracranial hemorrhage: a contemporary review. Crit Care. 2016;20:272. https://doi.org/10.1186/s13054-016-1432-0.

7. Efstathios Manios, Dariusz Gasecki, Antonio Coca, Pedro Cunha, Dagmara Hering, Dragan Lovic, and Cristina Sierra. Blood pressure targets in acute intracerebral hemorrhage: Scientific Newsletter Update Management of Hypertension. Eur Soc Hypertens. 2017, 18, nr. 64.
8. Shi L, Xu S, Zheng J, Xu J, Zhang J. Blood pressure management for acute intracerebral hemorrhage: a meta-analysis. Sci Rep. 2017;7(1):14345. https://doi.org/10.1038/s41598-017-13111-x.

9. Adnan I. Qureshi, Yuko Y. Palesch, William G. Barsan, Daniel F. Hanley, Chung Y. Hsu, Renee L. Martin et al., Intensive blood-pressure lowering in patients with acute cerebral hemorrhage. N Engl J Med 2016; 375, pp. 10331043. doi: https://doi.org/10.1056/NEJMoa1603460.

10. Lattanzi S, Silvestrini M. Optimal achieved blood pressure in acute intracerebral hemorrhage: INTERACT2. Neurology. 2015;85(6):557-8. https://doi.org/10.1212/01.wnl.0000470918.40985.d0.

11. Rabinstein AA. Optimal blood pressure after intracerebral hemorrhage. Stroke. 2018;49(2):275-6.

12. Moullaali TJ, Wang X, Woodhouse LJ, Law ZK, Delcourt C, Sprigg N, et al. Lowering blood pressure after acute intracerebral hemorrhage: protocol for a systematic review and meta-analysis using individual patient data from randomized controlled trials participating in the Blood Pressure in Acute Stroke Collaboration (BASC). BMJ Open. 2019;(7):e030121.

13. Qureshi Al, Palesch YY, Foster LD, Barsan WG, Goldstein JN, Hanley DF, Hsu CY, Moy CS, Qureshi MH, Silbergleit R. Blood pressure-attained analysis of ATACH 2 trial. Stroke. 2018;49:1412-8. https://doi.org/10.1161/STROKEAHA. 117.019845.

14. Hemphill JC, 3rd, Greenberg SM, CSK Anderson, et al. American Heart Association Stroke, C. Council on, N. Stroke, C. Council on Clinical, guidelines for the management of spontaneous intracerebral hemorrhage: a guideline for healthcare professionals from the American Heart Association/American Stroke Association. Stroke 2015; 46:2032-2060. doi.https://doi.org/10.1161/ STR.0000000000000069.

15. Hemphill JC 3rd, Bonovich DC, Besmertis L, Manley GT, Johnston SC. The ICH score: A simple, reliable grading scale for intracerebral hemorrhage. Stroke. 2001;32:891-7.

16. Banks JL, Marotta CA. Outcomes validity and reliability of the modified Rankin scale: Implications for stroke clinical trials: A literature review and synthesis. Stroke. 2007;38:1091-6.

17. Maeda AK, Aguiar LR, Martins C, et al. Hematoma volumes of spontaneous intracerebral hemorrhage: the ellipse $(A B C / 2)$ method yielded volumes smaller than those measured using the planimetric method. Arq Neuropsiquiatr. 2013;71:540-4.

18. Hu TT, Yan L, Yan PF, et al. Assessment of the ABC/2 method of epidural hematoma volume measurement as compared to computer-assisted planimetric analysis. Biol Res Nurs. 2016;18:5-11.

19. Shi J, Cai Z, Han W, Dong B, Mao Y, Cao J, et al. Stereotactic catheter drainage versus conventional craniotomy for severe spontaneous intracerebral hemorrhage in the basal ganglia. Cell Transplant:1-8. https://doi.org/10.1177/0963689719852302.

20. Esmael A, El Sherif M, Saad M. Prediction of 30-days mortality of intracerebral hemorrhage by a powerful but easy to use intracerebral hemorrhage score. Int Neuropsychiatric J. 2016;6(2):1-11.

21. Lim-Hing K, Rincon F. Secondary hematoma expansion and perihemorrhagic edema after intracerebral hemorrhage: from bench work to practical aspects. Front Neurol. 2017;8:74. https://doi.org/10.3389/fneur. 2017.00074.

22. Wang $X$, Arima H, Heeley E, Delcourt C, Huang Y, Wang J, et al. Magnitude of blood pressure reduction and clinical outcomes in acute intracerebral hemorrhage novelty and significance intensive blood pressure reduction in acute cerebral hemorrhage trial study. Hypertension. 2015;65(5):1026-32.

23. Wang X, Arima H, Al-Shahi Salman R, Woodward M, Heeley E, Anderson CS, et al. Rapid blood-pressure lowering according to recovery at different time intervals after acute intracerebral hemorrhage: a pooled analysis of the INTERACT studies. Cerebrovasc Dis. 2015;39(3-4):242-8. https://doi.org/10.1159/000381107.

24. Yamada T, Natori Y. Acute blood-pressure management and prognostic factors in patients with intracerebral hemorrhage. Interdiscip Neurosurg. 2017;10:91-5. https://doi.org/10.1016/j.inat.2017.07.013.

25. Smith KJ, Ainslie PN. Regulation of cerebral blood flow and metabolism during exercise. Exp Physiol. 2017;102(11):1356-71. https://doi.org/10.1113/ EP086249.

26. Rådholm K, Arima H, Lindley Rl, Wang J, Tzourio C, et al. Older age is a strong predictor for poor outcome in intracerebral hemorrhage: the INTERACT2 study. Age Ageing. 2015;44:422-7.

27. Lee S-H, Park K-J, Kang S-H, Jung Y-G, Park J-Y, Park D-H. Prognostic Factors of Clinical Outcomes in Patients with Spontaneous Thalamic Hemorrhage. Med Sci Monit. 2015;21:2638-46. https://doi.org/10.12659/MSM.894132. 
28. Hokari M, Shimbo D, Asaoka K, Uchida K, Itamoto K. Impact of antiplatelets and anticoagulants on the prognosis of intracerebral hemorrhage. J Stroke Cerebrovasc Dis. 2018;27(1):53-60. https://doi.org/10.1016/j. jstrokecerebrovasdis.2017.05.016.

29. Garg R, Biller J. Recent advances in spontaneous intracerebral hemorrhage[version 1; referees: 2 approved]. F1000 Res. 2019;8:302 Last updated: 18 MAR 2019

30. Sprügel MI, Kuramatsu JB, Gerner ST, Sembill JA, Beuscher VD, Hagen M, et al. Antiplatelet therapy in primary spontaneous and oral anticoagulationassociated intracerebral hemorrhage. Stroke. 2018;49:2621-9. https://doi.org/ 10.1161/STROKEAHA.118.021614.

31. Yogi N, Thulung, Sharma P. Clinico-radiological factors affecting outcomes of supratentorial spontaneous intracerebral hemorrhage: a single institute experience. Nepalese J Radiol. 2019;9(1):12-7. https://doi.org/10.3126/njr. v9i1.24809.

32. Trifan G, Arshi B, Testai FD. Intravenrrhtricular hemorrhage severity as a predictor of outcome in intracerebral hemorrhage. Front Neurol. 2019;10: 217. https://doi.org/10.3389/fneur.2019.00217.

33. Nag C, Das K, Ghosh M, Khandakar MR. Prediction of clinical outcome in acute hemorrhagic stroke from a single CT scan on admission. N Am J Med Sci. 2012;4(10):463-7. https://doi.org/10.4103/1947-2714.101986.

34. Niesen W-D, Schlaeger A, Bardutzky J, Fuhrer H. Correct Outcome prognostication via sonographic volumetry in supratentorial intracerebral hemorrhage. Front Neurol. 2019;10:492. https://doi.org/10.3389/fneur.2019. 00492.

35. Chen R, Wang X, Anderson CS, Robinson T, Lavados PM, Lindley Rl, et al. Infratentorial intracerebral hemorrhage: relation of location to outcome. Stroke. 2019;50:1257-9. https://doi.org/10.1161/STROKEAHA.118.023766.

36. Samarasekera N, Fonville A, Lerpiniere C, Farrall AJ, Wardlaw JM, White PM, et al. Influence of intracerebral hemorrhage location on incidence, characteristics, and outcome: population-based study. Stroke. 2015:46:361-8. https://doi.org/10.1161/STROKEAHA.114.007953.

37. Zhang H-X, Fan Q-X, Xue S-Z, Zhang M, Zhao J-X. Twenty-four-hour blood pressure variability plays a detrimental role in the neurological outcome of hemorrhagic stroke. J Int Med Res. 2018;46(7):2558-68. https://doi.org/10. 1177/0300060518760463.

38. Manning L, Hirakawa Y, Arima H, Wang X, Chalmers J, Wang J, et al. Blood pressure variability and outcome after acute intracerebral haemorrhage: A post-hoc analysis of INTERACT2, a randomised controlled trial. Lancet Neurol. 2014;13:364-73. https://doi.org/10.1016/S1474-4422(14)70018-3.

39. Tanaka E, Koga M, Kobayashi J, Kario K, Kamiyama K, Furui E, et al. Blood pressure variability on antihypertensive therapy in acute intracerebral hemorrhage: The stroke acute management with urgent risk-factor assessment and improvement-intracerebral hemorrhage study. Stroke. 2014; 45:2275-9. https://doi.org/10.1161/STROKEAHA.114.005420.

40. Anderson CS, Heeley E, Huang Y, Wang J, Stapf C, Lavados P, et al. For the INTERACT2 investigators rapid blood-pressure lowering in patients with acute intracerebral hemorrhage. N Engl J Med. 2013;368:2355-65. https://doi.org/10.1056/NEJMoa1214609.

41. Chu S, Sansing L. Evolution of blood pressure management in acute ICH. F1000Res. 2017;6:2035. https://doi.org/10.12688/f1000research.11687.1.

42. Qureshi Al, Palesch YY, Martin R, Novitzke J, Cruz-Flores S, Ehtisham A, et al. Effect of systolic blood pressure reduction on hematoma expansion, perihematomal edema, and 3-month outcome among patients with intracerebral hemorrhage: results from the antihypertensive treatment of acute cerebral hemorrhage study. Arch Neurol. 2010;67(5):570-6.

\section{Publisher's Note}

Springer Nature remains neutral with regard to jurisdictional claims in published maps and institutional affiliations.

\section{Submit your manuscript to a SpringerOpen ${ }^{\oplus}$ journal and benefit from:}

- Convenient online submission

- Rigorous peer review

- Open access: articles freely available online

- High visibility within the field

- Retaining the copyright to your article

Submit your next manuscript at $\boldsymbol{\nabla}$ springeropen.com 